\title{
The Sustainable Development Goals and Information and Communication Technologies
}

\author{
Peter Jones ${ }^{1 *}$, Martin Wynn', David Hillier², and Daphne Comfort ${ }^{1}$ \\ ${ }^{1}$ University of Gloucestershire, Business School, Cheltenham, UK \\ ${ }^{2}$ University of South Wales, Centre for Police Sciences, Pontypridd, Wales, UK \\ *Correspondence to: Peter Jones, University of Gloucestershire, Business School, \\ Park Campus, Cheltenham, GL 50 2RH, UK. \\ E-mail: pjones@glos.ac.uk
}

\begin{abstract}
The Sustainable Development Goals (SDGs) are a wide range of global sustainable development targets for the environment, society and economy and they were launched by the United Nations in 2015. In launching the SDGs, the United Nations called on all member states to embrace what are an ambitious and demanding set of challenges but it also emphasised the vital role that businesses, would have to play if these challenges were to be met. The aim of this preliminary commentary paper is to review a number of the ways the Information Communication and Technology industry believes it can contribute to the achievement of the SDGs. The paper outlines the characteristics of the concept of sustainable development and how ICT relates to sustainable development, reviews a number of the ways two leading ICT companies, namely Ericsson and Microsoft and two industry bodies, namely the GSMA which represents the interests of mobile operators worldwide, and the Global e-Sustainability Initiative, believe they can contribute to the achievement of the SDGs. The paper also examines some of the challenges the industry may face in making such a contribution and offers some reflections on the role of ICT in promoting the transition to a more sustainable future for people and the planet.
\end{abstract}

Keywords: sustainable development goals, information and communication technologies, business engagement, stakeholders, external assurance, economic growth.

Article info: Received 23 March 2017; revised 30 March 2017; accepted 3 April 2017

Recommended citation: Jones, P., Wynn, M., Hillier, D., \& Comfort, D. (2017). The Sustainable Development Goals and Information and Communication Technologies. Indonesian Journal of Sustainability Accounting and Management, 1(1), 1-15.

DOI: 10.28992/ijsam.v111.22

'Two issues of profound importance lie at the heart of current thinking about the development of global economies and societies: the challenge of environmental sustainability and the potential of information and communications technology' (Souter et al., 2010).

\section{Introduction}

The United Nations Sustainable Development Goals (SDGs), agreed in September 2015, were described as 'a plan of action for people, planet and prosperity' (Https://sustainabledevelopment.un.org, 2015). The SDGs have been described as demonstrating 'the scale and ambition' of the United Nations '2030 Agenda for Sustainable Development' which is designed to 'shift the world on to a sustainable and resilient path' 
(Https://sustainabledevelopment.un.org, 2015). In total, there are 17 SDGs, and 169 associated targets, in what is a comprehensive and ambitious vision for the future and the goals embrace a wide range of environmental, social and economic issues, including climate change, energy, water stewardship, marine conservation, biodiversity, poverty, food supply and security, sustainable production and consumption, healthcare, education, gender, equality, peace and economic growth. The United Nations called on all governments to develop national strategies to pursue the SDGs but also emphasised that business community had a vitally important role to play in addressing these goals.

A number of the leading information and communication technology (ICT) companies have suggested that their sector can play a central and vital role contributing to the achievement of the SDGs. Hans Vestberg, Ericsson's President and Chief Executive Officer, for example, argued that 'Information Communication Technology offers an incredible platform for achieving the SDGs' (Sachs et al., 2016). Mats Granryd, Director General of GSMA (the trade body that represents the interests of mobile telephone operators worldwide) suggested 'as an industry we have an important opportunity to leverage the mobile networks that we have built and the services we deliver to help achieve the Sustainable Development Goals' and more definitively that 'mobile networks ...... are essential in achieving the goals' (GSMA, 2016). More generally while recognising that 'the SDGs are the most ambitious set of global development goals ever agreed to' Global e-Sustainability Initiative (GeSI) and Accenture Strategy emphasised that 'digital solutions are indispensable: they transform the world quickly, with attractive propositions to people and with a positive impact to achieve all of the SDGs (Http://systemtransformation-sdg.gesi.org/, 2016). That said, ICT is not mentioned in any of the 17 SDGs and is noted in just 4 of the 169 targets. Indeed, Tim Unwin, Director of the ICT4 Collective, argued that 'the almost complete omission of ICTs from the final agreed SDGs was a very serious failing' and that 'those determining the SDG agenda for the next 15 years barely gave them any recognition at all' (Https://unwin.wordpress.com, 2015). With these thoughts in mind this preliminary commentary paper outlines the characteristics of the concept of sustainable development and how ICT relates to sustainable development, reviews a number of the ways the ICT industry believes it can contribute to the achievement of the SDGs, examines some of the challenges the industry may face in making such a contribution and offers some reflections on the role of ICT in promoting the transition to a more sustainable future for people and the planet.

\section{Sustainable Development and Information and Communication Technology}

The ideas underpinning sustainable development have long historical roots (Grober, 2012) but in modern times the concept began to attract increasing attention from the 1980 s onwards following the publication of the 'World Conservation Strategy' (Https://portals.iucn.org, 1980) and 'Our Common Future' (Http://www.undocuments.net, 1987). In the years since then the term sustainability has increasingly been seen as offering potential solutions to a wide range of challenges and problems from the global to the local scale across seemingly almost all walks of life. Barr (2008), for example, claimed that 'one of the most pressing and complex question of the early twentieth-first century' is 'how to promote the behavioural shifts necessary for creating the sustainable society.' The most widely used definition of sustainable development is 'development that meets the needs of the present without compromising the ability of future generations to meet their own needs' (Http://www.un-documents.net, 1987). However, sustainable development certainly 'means different things to different people' (Aras \& Crowther, 2008). On the one hand, there is a family of definitions essentially based in and around ecological principles and on the other, there are definitions which include social and economic development as well as environmental goals and which look to embrace equity in meeting human needs. At the same time a distinction is often made between 'weak' and 'strong' sustainable development with the former being used to describe sustainability initiatives and programmes developed within the prevailing 
economic and social system while the latter is associated with much more radical changes for both economy and society.

As such sustainable development has proved a compelling but an elusive paradox (Adelson et al., 2008). Ramirez (2012) for example, has argued that this paradox reflects the tension between the potentially positive effects of economic growth on poverty and employment with the damaging impact of such growth on the environment's natural resources and on traditional societies and ways of life in many parts of the less developed world. In a similar vein, on the one hand Adelson et al. (2008) have argued that under the banner of sustainable development significant strides have been made in protecting fragile environments, improving water supply and sanitation, installing irrigation systems and more generally in reducing poverty in many less developed economies. On the other hand Adelson et al. (2008) argued that the ambiguous nature of sustainable development means that it can be used by a variety of vested interests in the pursuit of their own goals. In many ways the launch of the SDGs is designed to provide a broad consensus and common sense of purpose to sustainable development across the globe.

ICT is widely seen as a powerful and pervasive force for change throughout economies and societies and can be defined as 'an umbrella term that includes any communication device or application, encompassing: radio, television, cellular phones, computer and network hardware and software, satellite systems and so on, as well as the various services and applications associated with them, such as videoconferencing and distance learning' (Rouse, 2005). However, in looking to work 'towards a new paradigm' for the relationship between 'ICTs, the Internet and sustainable Development' Souter et al. (2010) stressed that there had been 'surprisingly little interaction between policy makers and activists concerned with sustainable development and with ICT/Internet public policy.' The problem was seen to reflect 'the different interests of those concerned with sustainable development and with ICTs and internet public policy, and with the fact that the issues tend to be dealt with in different forums, among which there has been little interchange' (Souter et al., 2010). That said, in 2002 the European Information Technology Observatory (EITO) reported growing interest in 'the impacts and opportunities created for sustainable development by the rapid penetration of ICT into society and culture'. EITO (2002), for example, traced the growing convergence between the two policy agendas for sustainable development and the Information Society from the United Nations Earth summit in Rio de Janeiro in 1992 and the launch of the European Commission's "eEurope" strategy in 1999 up to the World Summit on Sustainable Development in Johannesburg in 2002.

In 2008 the Global e-Sustainability Initiative reported on the contribution the ICT industry could make to sustainable development across a range of issues including climate change; waste and material use; access to ICT; employee relationships; and economic development (Http://gesi.org, 2008). More recently, Hilty \& Hercheui (2014) have outlined a conceptual framework for an analytical approach to the relationship between ICT and sustainable development which involved deconstructing the 'normative concept of sustainable development' into ecological, social and economic dimensions and analysing ICT and sustainable development to identify levels of environmental impacts, the human, social and ecologically compatibility of ICT and ICT for development. Hilty \& Aebischer (2015) edited a review of how to use 'the transformational power of ICT to develop more sustainable patterns of production and consumption' which focuses on a wide variety of specific issues including smart sustainable cities; the energy demands of data centres; software support for supply chains; the recycling of ICT equipment; the energy intensity of the internet; and the interdependency of energy, information and growth.

More generally, two different, though certainly not mutually exclusive, themes are emphasised in much of the published material on the relationships between ICT and sustainable development. On the one hand, the role of ICT applications in supporting and facilitating sustainable development is a common theme. Tongia et al. (2005) provided a review of the role of ICT in less developed economies in addressing a wide range of 
sustainable development challenges including water supply and sanitation; energy supply; primary education; food supply; healthcare; and empowerment for women and minorities. In addressing the role of ICT in education, for example, Tongia et al. (2005) argued that 'ICT can help education and literacy, as it has the technological prowess of extended reach' that 'ICT can overcome some of the major handicaps inherent in conventional education' but also stressed that 'ICT should enhance or supplement traditional education not replace it.' On the other hand, growing numbers of companies increasingly see sustainable development offering a wide range of emerging business opportunities and are designing new, or modifying their existing, business models to profitably address such opportunities. Rivera \& Kurnia (2015), for example, argued that 'some organisations have planned sustainability strategies that not only minimize the environmental impact but also increase their business competitiveness' and cited a range of business benefits, including cost reductions, increases in sales, efficient resource consumption, creating competitive advantage and employee satisfaction and well-being, accruing to companies pursuing sustainability strategies.

In part, these two different themes might be seen to reflect the suggestion outlined above that sustainable development means different things to different people. At the same time these themes also mirror research which suggests that corporate sustainability strategies in both the retail and hospitality sectors of the global economy are driven as much by business imperatives as by any fundamental commitment to maintain the viability and integrity of natural and social capital (Jones et al., 2011; Jones et al., 2014). More conceptually, the two themes might be seen to reflect the 'discourse' of 'ecological modernisation' which 'is largely grounded in what is commonly referred to as the "business case" for sustainability' (Roper \& Collins, 2016). Roper \& Collins (2016) further argued that 'in many ways ecological modernisation lies within the discourse of sustainable development' with its focus being on 'practical and profitable solutions to environmental problems that allow the underlying economic model to continue.'

\section{Method of Enquiry}

Companies have employed a range of methods to report their sustainability strategies but publication on corporate websites has become the most popular and the most accessible reporting mechanism (Morhardt, 2010). With this in mind, and in an attempt to make a preliminary assessment of the ICT industry's policy towards the SDGs the authors searched the Internet using the key phrase 'SDGs and the ICT Industry', using Google as the search engine, in February 2017. This search revealed that two leading ICT companies, namely Ericsson and Microsoft, and two industry bodies, namely the GSMA and the Global e-Sustainability Initiative had published reports on the SDGs. Ericsson is a multinational networking and telecommunications equipment and services company with headquarters in Stockholm, Sweden. The company employs some 113,000 people, operates in some 180 countries and in 2016 it generated revenues of $\$ 24$ billion. Microsoft is an American multinational corporation that develops, manufactures, licenses, supports and sells computer software, consumer electronics and personal computers and services. The company employs some 114,000 people and in 2016 it generated revenues of $\$ 85$ billion. The GSMA is a trade body that represents the interests of some 800 mobile telephone operators worldwide via industry programmes, working groups and industry advocacy initiatives. The Global e-Sustainability Initiative works in collaboration with members from the world's leading ICT companies and organisations around the globe to offer information, resources and best practices for achieving integrated social and environmental sustainability through ICT.

A number of authors (e.g. de Grosbois, 2016; Newell, 2008) have employed forms of content analysis to systematically identify themes and issues within sustainability reports. However, the authors looked to base their current commentary on the reading and reflective review of the four reports. In taking this decision, the authors were minded that content analysis was not appropriate given the small number of reports being 
reviewed and that all four reports, though having their own house style and layout, were well structured and signposted, and thus a systematic quantitative assessment was not appropriate. The information from the reading and review process provided the information for this commentary paper. The aim is not to offer a detailed comparative analysis of different approaches to the SDGs within the ICT industry and the specific examples and quotations are employed primarily as illustrations. The commentary is based on information that is in the public domain and the authors took the considered view that they did not need to contact the selected companies to obtain formal permission prior to conducting their research.

When outlining the issues of reliability and validity in relation to information on the internet Saunders et al. (2009) emphasised the importance of the authority and reputation of the source and the citation of a specific contact individual who can be approached for additional information. In reviewing the sustainability reports the authors felt that the two conditions were met. The authors recognise that four selected reports cannot provide a comprehensive view of corporate thinking on how the ICT industry might contribute to the achievement of the SDGs. At the same time there are qualifications concerning the extent to which the reports fully reflect the policy thinking about the SDGs within the ICT industry, and there are reservations about whether or not the reports might be seen by some critics as carefully constructed public relations exercises. However, notwithstanding these issues, the authors believe that their approach offers an accessible window and an appropriate framework for the current preliminary study.

\section{The SDGs and the ICT Industry}

The SDGs are global development goals, agreed by the United Nations' member states that look to set the priorities for sustainable development through to 2030. There are some 17 SDGs (Table 1), which range from 'the wellbeing of every individual to the health of the planet, from infrastructure to institutions, from governance to green energy, peaceful societies to productive employment' (Https://www.ihrb.org, 2015) with each one having a number of associated targets. The ratification of the SDGs is the latest in the line of global sustainable development initiatives which can be traced back to the declaration designed 'to inspire and guide the peoples of the world in the preservation and enhancement of the human environment' (Http://staging.unep.org, 1972) following the United Nations Conference on the Human Environment held in Stockholm in 1971. More recently, the SDGs are seen to build on the United Nations' Millennium Development Goals (MDGs) established in 2001. The MDGs were described as having 'produced the most successful antipoverty movement in history' (Http://www.un.org, 2015) but other assessments of the achievements of the MDGs have been less positive. While Fehling et al. (2013), for example, acknowledged that 'remarkable progress has been made' they also suggested that 'progress across all MDGs has been limited and uneven across countries.' At the same time the involvement of the business community in the MDGs was limited with (PricewaterhouseCoopers, 2015) commenting 'business, for the most part, didn't focus on the MDGs because they were aimed at developing countries.'

The targets for 2030 for Goal 1, namely to end poverty in all its forms everywhere, include eradicating extreme poverty, measured as people living on \$1.25 per day, ensuring that all men and women and particularly the poor and vulnerable have equal rights to economic resources, access to basic services and ownership and control over land and property; and building the resilience of the poor and vulnerable to reduce their exposure to climate change and related extreme events. For Goal 6, namely to ensure availability and sustainable management of water and sanitation for all the 2030 targets include achieving universal and equitable access to safe and affordable drinking water for all: protecting and restoring water related ecosystems; and improving water quality by reducing pollution, eliminating dumping and minimising the release of hazardous chemicals. Targets for Goal 12, namely to ensure sustainable consumption and production patterns include achieving the 
sustainable management and efficient use of natural resources by 2030; halving per capital global food waste at the retail and consumer levels and reducing food losses within production and supply chains by 2030; and designing and implementing tools to monitor sustainable development impacts for sustainable tourism that creates jobs and promotes local culture and local products.

Table 1 The Sustainable Development Goals

\begin{tabular}{ll}
\hline No. & Goals \\
\hline 1. & End poverty in all its forms everywhere \\
2. & End hunger, achieve food security and improved nutrition and promote sustainable agriculture \\
3. $\quad$ Ensure healthy lives and promote well-being for all at all ages \\
4. $\quad$ Ensure inclusive and equitable quality education and promote lifelong learning opportunities for all \\
5. $\quad$ Ensure availability and sustainable management of water and sanitation for all \\
7. $\quad$ Ensure access to affordable, reliable, sustainable and modern energy for all \\
8. $\quad$ Promote sustained, inclusive and sustainable economic growth, full and productive employment and decent
\end{tabular}
work for all

9. Build resilient infrastructure, promote inclusive and sustainable industrialization and foster innovation

10. Reduce inequality within and among countries

11. Make cities and human settlements inclusive, safe, resilient and sustainable

12. Ensure sustainable consumption and production patterns

13. Take urgent action to combat climate change and its impacts

14. Conserve and sustainably use the oceans, seas and marine resources for sustainable development

15. Protect, restore and promote sustainable use of terrestrial ecosystems, sustainably manage forests, combat desertification, and halt and reverse land degradation and halt biodiversity loss

16. Promote peaceful and inclusive societies for sustainable development, provide access to justice for all and build effective, accountable and inclusive institutions at all levels

17. Strengthen the means of implementation and revitalize the global partnership for sustainable development Source: Https://sustainabledevelopment.un.org (2015)

The four reports emphasised both the ICT industry's belief that it has a vital role to play in contributing to the SDGs and the industry's commitment to making and publicly promoting that potential contribution. The Global e-Sustainability Initiative (GeSI), for example, argued that 'digital solutions from all areas of life can directly contribute to SDG achievements' and more pointedly that 'digital solutions are indispensable, they transform the world quickly, with attractive propositions to people and with a positive impact to achieve all of the SDGs (Http://systemtransformation-sdg.gesi.org/, 2016). Microsoft stressed that the company sought 'to apply the unique assets that a technology company of our scope and scale has towards the global multi-sector 
effort needed to achieve the SDGs' (Https://www.microsoft.com, 2016). Sachs et al (2016) visualised ICT as 'a catalyst for achieving the SDGs' and argued that 'ICT, especially mobile broadband, will be the essential infrastructure platform for the SDGs and that 'rapid action is needed to harness the contribution that ICT can make toward the achievement of the Global Goals' (Sachs et al., 2016).

More specifically while the ICT industry generally stressed its belief that 'digital solutions catalyse the achievement of all SDGs' (Http://systemtransformation-sdg.gesi.org/, 2016) and that 'all SDGs are impacted by the mobile industry to varying degrees' GSMA (2016), the focus of the ICT industry's contribution seems to be primarily focused on a more limited, but varied, range of the SDGs. Microsoft, for example, have 'prioritized 8 SDGs to ensure we leverage our assets for the greatest impact' and the company has focused its principal attention on SDGs 3, 4, 5, 8, 9, 11, 13, and 16, because of their 'particular alignment with Microsoft's business and philanthropic strategies' (Https://www.microsoft.com, 2016). In addressing SDG 8, namely Decent Work and Economic Growth, for example, Microsoft claimed to work with a global spread of governments, development agencies and non-governmental organisations, to promote economic development and to empower entrepreneurs and business leaders with the tools, skills and opportunities to stimulate and facilitate economic growth. As illustrative examples of its work Microsoft cites 'Kenya AGIN', which is a cloud based service which uses farmer profile and production data to help farmers establish their creditworthiness and its work with India's Ministry of Rural Development to develop a skills matching and payments solutions to help some 128 million workers find employment. In addressing SDG 3, namely Good Health and Well Being, Microsoft reported on its role in providing products, services and training to help governments and health care providers to 'understand how to apply technologies like advanced data analytics and cloud solutions to transform healthcare' (Https://www.microsoft.com, 2016).

The GSMA chose a more tightly focused approach 'identifying the SDG targets that the mobile industry can impact in a significant way' GSMA (2016), namely SDGs 1, 4, 9, and 13. That said, the GSMA (2016) argued that its choice 'does not imply prioritisation on behalf of the industry' rather it reflects the SDGs, and associated targets, 'that can currently be materially influenced by what the industry currently does' and 'the importance of the industry to those targets.' At the same time, the GSMA (2016) reported that its choice was also determined by the exclusion of those SDGs that emphasised state policy and/or intervention rather than the existence of a 'compelling mobile industry driver.' The GSMA claimed that the industry plays an important role in helping to eradicate poverty and providing equal access to economic resources and building the resilience of the poor (SDG 1) by 'stimulating economic participation and activity through voice and data services, providing affordable connectivity, and acting as a provider of financial services to developing economies including the powerful platform of mobile remittances that is particularly valuable to underserved communities.' In addressing SDG 4, namely, Quality Education, the GSMA suggests that the ICT industry provides connectivity to schools and learners and access to educational platforms and facilitates the purchase of school related services to less developed economies via mobile money transfers.

The GeSI (Http://systemtransformation-sdg.gesi.org/, 2016) identified seven SDGs, namely 6, 7, 11, 12, 13, 14 , and 15 as being focused on protecting the environment while looking to ensure 'that other goals are achieved without breaching the planet's ability to regenerate for future generations.' Smart water management, for example, was identified as the most powerful digital solution to contribute to the achievement of SDG 6, namely Availability Clean Water and Sanitation, and here specific solutions included smart pipes, smart levees, smart meters, soil sensors, remote irrigation management, rain water harvesting systems, consumption control applications and e-billing. In addressing SDG 12, namely Sustainable Consumption and Production, the focus was on smart manufacturing and smart agriculture. The former included the Industrial Internet of Things, 3-D printing, data analytics and cloud computing, drones and robotics and embedded system production technologies while the latter included automated irrigation systems and 
real time weather information, traceability and tracking systems. Sachs et al. (2016) looked to demonstrate 'the potential of ICT to drive progress on the SDGs' in four areas namely financial services; education; health; and energy and climate change.

All four reports specifically identify SDG 13, namely Action on Climate Change, as a priority. The GeSI (Http://systemtransformation-sdg.gesi.org/, 2016), for example, identified three of the targets under SDG 13, namely, strengthening resilience and adaptive capacity to climate related hazards and natural disasters; integrating climate change measures into national policies and planning; and improving educational awareness and human and institutional capacity on climate change mitigation; as being the most likely to benefit from digital solutions. Indeed the GeSI (Http://systemtransformation-sdg.gesi.org/, 2016) argued 'luckily digital solutions have an enormous potential to reduce greenhouse gas emissions' and suggested that 'smart manufacturing, smart agriculture, smart buildings, smart mobility and smart energy' could cut global greenhouse gas emissions by some $20 \%$ by 2030 . GHG emissions by a firm are of concern to multiple stakeholders as it affects their interest. These concerns emanate from the likely cost the firm may have to face to comply with government regulations on one hand and the possibilities of penalties if the firm fails to comply (Rokhmawati \& Gunardi, 2017). Arguably more tellingly the GeSI (Http://systemtransformation-sdg.gesi.org/, 2016) also suggested that 'these digital solutions can help us to hold emissions at current levels while enabling the huge strides in equitable growth and quality of life' and optimistically further suggested that 'at the very least, digital solutions can help us to stabilize global climatic conditions that are recognizable today - while enabling economic growth to do its work in lifting people out of poverty.' Microsoft reported on its carbon neutrality strategy and on achieving carbon neutrality spanning over 100 countries in its data centres, software development labs, offices and company owned manufacturing plants. The company's carbon neutrality strategy is underpinned by a 'chargeback model' which 'puts a price on carbon and makes the company's business divisions responsible for the cost of reducing and compensating for carbon emissions associated with their electricity use and air travel' while the resultant 'carbon fee funds energy efficient investments' (Https://www.microsoft.com, 2016).

There is varying recognition within the four reports that the role, and the impact, of the ICT industry in contributing to the SDGs, will vary in different parts of the world. Generally, this is implicitly recognised in discussing the different potential for impact in urban and rural areas and between developed and less developed economies. More explicitly the GSMA reported on variations in the future opportunities for the mobile industry to impact on economies at different stages of development and in different geographic regions. In addressing the former the GSMA (2016) reported that within 'developed' economies the mobile industry would have a high impact on SDGs 13 (Action for Climate Change), 5 (Gender Equality), 8 (Decent Work and Economic Growth) and 11 (Sustainable Cities and Communities). In contrast the GSMA (2016) reported that the overall impact of mobile industry within 'developing' economies will be lower than the global average and that would be most marked in relation to SDG 13 (Action for Climate Change) and SDG 7 (Affordable and Clean Energy). Variations in the future opportunities for the mobile industry to impact on the SDGs were also identified across geographical space. In the Asia Pacific region, for example, the GSMA (2016) reported that the current impact on many of the SDGs is limited by low penetration of mobile services and that efforts to address SDG1 (No Poverty) 'will require specific focus on how to increase the value of services, particularly mobile broadband through a combination of affordability and relevant local content.' Similar challenges are identified as facing the mobile industry in Sub-Saharan Africa but in this region the GSMA (2016) also suggested that 'in addition to increasing the reach of its services, it is equally important for the industry to play a leading role to promote transparency and ethical business practices within its own operations'. By way of contrast within Europe the impact of the mobile industry is seen to be high across most of the SDGs but the GSMA (2016) suggested that there is scope to increase the impact on SGD 17 (Partnership for the Goals) through the ICT 
industry's leadership of 'multi-stakeholder partnerships, driving co-ordination of the sustainable development agenda, as well as continuing to develop and implement open platforms that enable innovation ecosystems and provide a blueprint for other regions to follow.'

While the general tone of all four reports is positive and enabling there is a recognition within the ICT industry that a range of barriers and challenges need to be addressed if the industry is to play a full role in contributing to the achievement of the SDGs. The GeSI (Http://systemtransformation-sdg.gesi.org/, 2016), for example, looked to address 'the hurdles the world needs to clear in order to deploy the digital solutions needed to meet the UN's ambitious deadline for achieving the SDGs.' More specifically the GeSI (Http://systemtransformation-sdg.gesi.org/, 2016) suggested that there were two sets of hurdles namely 'barriers to ICT deployment that hold up the scaling of digital solutions on a global basis' and 'people's concerns about some aspects of digital solutions' which 'limit the diffusion of some innovative digital solutions.' The first set was seen to include political and regulatory blockages, lack of capital to provide the necessary infrastructure and lack of suitable digital skills amongst potential end users and entrepreneurs. Financial barriers are seen to be most acute within less developed economies, where sustainability challenges are often most pressing, and the GeSI (Http://systemtransformation-sdg.gesi.org/, 2016) called on 'the private sector and policy makers alike to create a financial environment that fosters digital innovations that further sustainable development.' The second set of hurdles includes concerns about digital trust, avoiding cyber-crime, possible negative impacts on employment and reducing the ICT sector's footprint. In addressing employment impacts, for example, the GeSI (Http://systemtransformation-sdg.gesi.org/, 2016) suggested that 'it is imperative that societies adequately prepare people to anticipate changing requirements in the labor market and enable them to pick up the right skills to maximize their employment potential.'

Sachs et al. (2016) argued 'the role of ICT in the SDG era (2016-2030) will evolve rapidly' but identified a number of 'practical hurdles' (Sachs et al., 2016) to the effective widespread deployment of ICT in helping to achieve the SDGs. These hurdles included public sector regulation which does not yet enable full utilisation of $I C T$, the need for rapid expansion and upgrading of wireless broadband particularly in rural areas, the training of personnel to operate and manage ICT systems and the incubation of new ICT start-ups. More generally Sachs et al. (2016) argued that 'fulfilling the SDGs calls for multi-sectoral partnerships' and that 'many of the challenges of sustainable development - health, education, infrastructure and environmental sustainabilityrequire a deep role for policy makers and the public sector to drive progress by 2030.' Further Sachs et al. (2016) suggested that 'to harness ICT effectively for the 2030 Agenda ...... governments need to ensure that the entire public sector, including service delivery in health, education, energy and infrastructure, is fully supported by high-quality ICT infrastructure.' This would, inter alia, involve promoting ICT as a basic infrastructure in urban and rural planning and investment, ICT training of all public officials and service providers and the adoption of state of the art indicators and real time data collection to monitor progress against the SDGs.

\section{Discussion}

At a time when some reports (e.g. Https://corporate-citizenship.com, 2016) suggest the majority of businesses have been slow to engage with the SDGs, the ICT industry has been keen to emphasise what it sees as its key role in contributing to the achievement of the SDGs. That said four wider sets of issues merit discussion and reflection. Firstly, it is important to recognise that the ICT industry sees the SDGs as a major new business opportunity. Under the banner 'Sustainable Development Makes Good Business Sense' the GeSI (Http://systemtransformation-sdg.gesi.org/, 2016) claimed that 'the digital solutions that catalyse SDG achievement' could generate ' $\$ 3.1$ trillion of additional annual revenue to the sector, from rolling out a range of established and emerging technologies across all markets.' This 'would represent a huge growth boost of 
60\%' to the ICT industry. In addition to these new revenues the GeSI (Http://systemtransformationsdg.gesi.org/, 2016) suggested that making a full contribution to the SDGs would also bring several intangible benefits to the ICT industry. Such benefits could include brand enhancement, associated with major players within the ICT industry becoming increasingly recognised for their role, for example, in monitoring and mitigating climate change, and the increased demand for data driven products and services generated by the improvements in lifestyles brought about by the fulfilment of the SDGs. The GSMA (2016) stressed the importance of 'a sustainable commercial model' to underpin the mobile industry's commitment to the SDGs and positively concluded that the future "holds very significant opportunities as the world seeks to benefit from digitisation and the connectivity that underpins it' (GSMA, 2016).

As such, a focus on the business opportunities for the ICT industry associated with the SDGs might be seen to resonate with the concept of shared value. This concept is typically defined as 'policies and practices that enhance the competitiveness of a company while simultaneously addressing the economic and social conditions in the communities in which it operates' (Porter \& Kramer, 2006). More generally the Shared Value Initiative has suggested that the SDGs offer an 'opportunity for people running businesses to cash in on the huge market potential in solving the most pressing issues of our time' and more pointedly claimed that 'the SDGs are the most tangible way to date to find business opportunity in social problems.' However Crane et al. (2014) identified a number of weaknesses and shortcomings in the creation of the shared value model. More specifically Crane et al. (2014) argued that the model 'ignores the tensions between social and economic goals' that it is 'naïve about the challenges of business compliance' and that it is 'based on a shallow conception of the corporation's role in society.' In examining the first of these concerns, for example, Crane et al. (2014) suggested that 'many corporate decisions related to social and environmental problems, however creative the decision-maker may be, do not present themselves as potential win-wins, but rather manifest themselves in terms of dilemmas.' As such Crane et al. (2014) suggested that such dilemmas are effectively 'continuous struggles between corporations and their stakeholders over limited resources and recognition.' In justifying their assertion that creating shared value is based on a shallow reading of the corporation's role in society Crane et al. (2014) argued that the model seeks to 'rethink the purpose of the corporation without questioning the sanctity of corporate self-interest.'

Secondly, 'connecting the unconnected' Sachs et al. (2016) is universally seen as being a critical component that the ICT industry can make in the achievement of the SDGs. The GSMA (2016), for example, stressed the importance of 'extending network coverage to rural areas' but arguably more importantly recognised that while connectivity 'is a very important first step' the real prize is about 'what this connectivity enables' namely 'connecting everyone and everything to a better future.' In many ways this is globalisation positively cast, and Sachs (2016), for example, has described the SDGs as 'a new kind of globalization' but as such it might be seen to be in conflict with the underlying spirit of the SDGs in a number of ways. The standardisation of products and services and the seemingly all pervasive power of a relatively small number of global brands within the ICT industry, for example, presents almost insurmountable barriers to small local entrepreneurs and producers within less developed economies. There are risks that increases in trade often associated with globalisation can not only accelerate the exploitation of non-renewable natural resources but also lead to increases in pollution and greenhouse gas emissions and as such undermine the SDGs. Where local economies increasingly concentrate on the production of a limited range of products and services to meet the demands of global markets a downturn in these markets can have damaging consequences for local economies. Ultimately many critics would argue that globalisation does not offer a better future for everyone, rather it produces winners and losers, and that it serves to exacerbate, rather than reduce, inequalities between developed and less developed economies. 
Thirdly, while the ICT industry has certainly emphasised its commitment to contributing to the achievement of the SDGs it has also argued that governments have a vital enabling role in allowing the industry to make that contribution. This raises issues about the role of the state within society and here there are both policy and conceptual issues. Turning first to policy French (2002) argued that many states have sought to promote sustainable development through 'a restricted public sphere paradigm which places greater emphasis on the corporate imperative' namely that the state must not jeopardise 'the competitiveness of corporate interests in the wider global economy.' That said there appear to be contradictions in the policy role the ICT industry would like to see governments playing. On the one hand the GeSI (Http://systemtransformationsdg.gesi.org/, 2016) has called on governments to play 'their part in shaping policy and legal frameworks' by 'liberalising some markets, improving the ease of doing business and bearing down on restrictive practices' and thereby reducing the regulatory role of the state. On the other hand, the ICT industry is generally united in calling for government investment in wholesale improvements in connectivity in less developed economies. More generally for French (2002) sustainable development raises fundamental questions about the 'public/private-public/corporate' and while he calls for 'a more collaborative approach' he offers little by way of a prescription of how this is to be achieved. At a conceptual level a liberal pluralist perspective sees the state as a neutral arbiter of social processes, which provides opportunities for all stakeholders to influence state policy and which works for the benefit of society as a whole. Such an approach strikes a chord not only with the ICT industry's position on the SDGs but also echoes the United Nations' call for governments and the private sector to work closely together to address the SDGs. By way of contrast political economy perspectives on the role of the state are broadly based on the belief that within capitalist societies, rather than being a neutral arbiter, the state will always act in such a way to ensure that the long-term interests of capital are always dominant. Such a reading of the role of the state might see the interests of capital overriding the need for a more radical approach in looking to achieve the SDGs.

Fourthly, there are potentially more fundamental tensions between the ICT industry's commitments to future growth, and thus more generally to continuing economic growth, and the achievement of the SDGs. The ICT industry's commitment to the SDGs is essentially predicated on continuing growth. Sachs et al. (2016) explicitly links 'rapid economic growth and SDG success' and in addressing SD7 (Decent Work and Economic Growth) the GSMA (2016) looked to 'sustain per capita economic growth in accordance with national circumstances and, in particular, at least 7 per cent gross domestic product growth per annum in the least developed countries.' However many critics argue that such growth will make increasingly severe demands on the Earth's finite natural resources and there are concerns that these demands and the continuing corporate commitment to growth that drive them will prove ultimately unsustainable. Higgins (2013), for example argued 'the economic growth we know today is diametrically opposed to the sustainability of our planet.' The counter argument is focused on the notion of sustainable economic growth and on 'decoupling economic growth from environmental degradation' (GSMA, 2016).

That said while the GSMA (2016), for example, recognised the need 'to ensure that growth remains within safe planetary limits' the ICT industry does not explicitly look to define sustainable economic growth. Thus while, the GSMA (2016) has claimed that 'sustainable business practices stem from companies establishing a deep rooted system of values' and that this system should meet 'fundamental responsibilities in the areas of environment, labor, supply chain, human rights and ant-corruption' there is no suggestion of how these responsibilities are to be met or the potentially fundamental changes in business practices such a value system would surely demand. More generally within the ICT industry the term sustained economic growth seems to be used almost universally to refer to the perceived importance of securing continuing economic growth rather than to explaining how such growth is to be achieved within finite environmental limits. At the same time decoupling is seen by some critics as an elusive goal and Conrad \& Cassar (2014) suggested that 'a 
substantial body of research has cast doubts on whether countries can truly grow their way out of environmental problems.' While Jackson (2009) recognised that the 'conventional response to the dilemma of growth is to call for decoupling' he highlighted the importance of distinguishing between 'relative' and 'absolute' decoupling. The former refers to the decline of resource impacts relative to growth and the latter signifies an absolute decline in such impacts. Although some large corporations might claim to support relative decoupling through their commitments to efficiency, they currently show little enthusiasm for absolute decoupling which Jackson (2009) believed 'is essential if economic activity is to remain within ecological limits.' Arguably more radically Jackson (2009) concluded a discussion of what he described as 'the myth of decoupling' by arguing that 'it is entirely fanciful to suppose that deep emission and resource cuts can be achieved without confronting the structure of market economies.'

Technology and technological innovation are often seen to be vitally important in improving efficiency across the sustainability spectrum and in helping to deliver sustainable growth. Clark \& Dickson (2003), for example, suggested that 'the need for sustainable development initiatives to mobilize appropriate science and technology has long been recognized' and advances in technology are often seen to provide the best way of promoting greater efficiency. More specifically, Sachs et al. (2016), for example, argued that 'ICTs have the potential to increase the rate of diffusion of a very wide range of technologies across the economy' and 'the accelerated up take of these technologies ...... constitute the key to achieving the SDGs by their target date of 2030.' However (Schor, 2005) claimed that 'advocates of technological solutions argue that more intelligent design and technological innovation can dramatically reduce or even stop the depletion of ecological resources, as well as eliminate toxic chemicals and ecosystem disruption.' In a similar vein (Schor, 2005) argued that such approaches 'fail to address increases in the scale of production and consumption, sometimes even arguing that such increases are not unsustainable if enough natural-capital-saving technical change occurs.'

More optimistically, the unprecedented nature and pace of technology development within the ICT industry might be seen to offer sustainable solutions to seemingly elusive environmental and social challenges and might thus allow the ICT industry to make a major and lasting contribution to the SDGs. Heeks (2014) for example, noted that ICT products and services that are currently to the fore for use in developing countries are 'near-ubiquity of mobile, spread of broadband, more big/open/real-time data, use of field sensors/embedded computing, more social media, more crowd-sourcing models, more cloud, more smartphones, and 3D printing', but that the scope, reach and depth of ICTs in developing countries is changing apace. Heeks (2017a) noted that 'the relationship between digital ICTs and international development can be divided into three paradigms - pre-digital, ICT4D, and digital development'. The digital paradigm is now on the ascent and will overtake the ICT4D paradigm by 2030.

The ICT4D paradigm emerged in the mid-1990s, and arose 'because of the rough synchrony between general availability of the Internet - a tool in search of purposes, and the Millennium Development Goals - a purpose in search of tools' Heeks (2017a). Heeks (2017b) asserted that now 'integrationism is progressing, mainstreaming ICTs as a tool to achieve the various development goals' and that a 'new digital development paradigm' is emerging. In practice, this means that the nature and potential impact of ICT solutions in support of the SDGs will take increasingly new forms in the years up to 2030 as new digital platforms become available. ICTs are therefore moving, in developing countries, from 'a specialist tool to an everyday utility with digital mediation, emerging as the dominant mechanism for many processes of economic, political and cultural development' (Heeks, 2016). Given some of the preceding discussion and the general absence of ICT concepts and actions in the SDGs, such a transformation may appear questionable. But the technological developments of the last thirty years and the increasing pace of change suggests Heeks' assertions are likely to prove correct, placing even more focus on the role of the ICT sector in support of the SDGs. ICTs may no longer be 'just tools to enable particular aspects of development, but the platform that mediates development' (Heeks, 2016). 


\section{Conclusion}

The SDGs certainly offer an ambitious and wide ranging global vision for a sustainable future. While the transition to such a future demands both political and economic commitment from governments, the United Nations has called on all businesses to play a central role in achieving the SDGs. While some businesses seem to have been slow to actively engage with the SDGs the ICT industry has stressed that it has a vital role to play in driving progress towards the global transformation that the SDGs demand. Monitoring and evaluating the role of the ICT industry in contributing to the achievement of the SDGs seems likely to be a complex and contested process and it is far too early to embark on such a major task. That said the ICT industry has certainly identified the SDGs as a massive business opportunity and this paper suggests that the industry is looking to develop what the GSMA (2016) described as the 'co-ordination and standardisation of the industry's messages globally' which is seen to be 'critical to achieve optimal results for all stakeholders.' However, the ICT industry has emphasised the vital importance of the role of governments in creating a more liberal market environment and in funding many of the necessary improvements in connectivity. Looking to the future the role of governments, particularly in less developed economies, in effectively addressing these challenges may prove problematic. Here the rapid pace of technological development within the ICT industry may revolutionise how the SDGs can be achieved. That said, for some critics the fundamental problem will continue to revolve around the tensions between the SDGs and continuing commitments to economic growth.

\section{References}

Adelson, G., Engell, J., Ranalli, B., \& Van Anglen, K. P. (2008). Environment: An Interdisciplinary Anthology. New Haven and London: Yale University Press. Retrieved from https://www.jstor.org/stable/j.ctt5vkqnr

Aras, G., \& Crowther, D. (2008). Governance and sustainability: An investigation into the relationship between corporate governance and corporate sustainability. Management Decision, 46(3), 433-448.

Barr, S. (2008). Environment and society: Sustainability, policy and the citizen. Aldershot: Ashgate.

Clark, W. C., \& Dickson, N. M. (2003). Sustainability science: the emerging research program. In Proceedings of the National Academy of Sciences of the United States of America (Vol. 100, pp. 8059-8061). http://doi.org/10.1073/pnas.1231333100

Conrad, E., \& Cassar, L. F. (2014). Decoupling Economic Growth and Environmental Degradation: Reviewing Progress to Date in the Small Island State of Malta. Sustainability, 6(10), 6729-6750. http://doi.org/10.3390/su6106729

Crane, A., Palazzo, G., Spence, L. J., \& Matten, D. (2014). Contesting the Value "Creating Shared Value" Concept. California Management Review, 56(2), 130-153. http://doi.org/10.1525/cmr.2014.56.2.130

de Grosbois, D. (2016). Corporate social responsibility reporting in the cruise tourism industry: a performance evaluation using a new institutional theory based model. Journal of Sustainable Tourism, 24(2), 245-269. http://doi.org/10.1080/09669582.2015.1076827

EITO. (2002). The impact of ICT on sustainable development. Retrieved February 15, 2017, from http://homepage.cs.latrobe.edu.au/sloke/greenIT/eito_forum_2002.pdf

Fehling, M., Nelson, B. D., \& Venkatapuram, S. (2013). Limitations of the Millennium Development Goals: a literature review. Global Public Health, 8(10), 1109-1122. http://doi.org/10.1080/17441692.2013.845676

French, D. A. (2002). The Role of the State and International Organizations inReconciling Sustainable Development and Globalization. International Environmental Agreements, 2(2), 135-150. http://doi.org/10.1023/A:1020912808651

Grober, U. (2012). Sustainability: A Cultural History. Cambridge: Green Books. 
GSMA. (2016). 2016 Mobile Industry Impact Report: Sustainable Development Goals. Retrieved January 23, 2017 , from https://www.gsma.com/betterfuture/wpcontent/uploads/2016/09/_UN_SDG_Report_FULL_R1_WEB_Singles_LOW.pdf

Heeks, R. (2014). ICT4D 2016: New Priorities for ICT4D Policy, Practice and WSIS in a Post-2015 World (No. 59). Development Informatics.

Retrieved from

http://hummedia.manchester.ac.uk/institutes/gdi/publications/workingpapers/di/di_wp59.pdf

Heeks, R. (2016). Examining "Digital Development": The Shape of Things to Come? (No. 64). Development Informatics.

Heeks, R. (2017a). An Emerging Digital Development Paradigm? Retrieved from http://blog.gdi.manchester.ac.uk/emerging-digital-development-paradigm/

Heeks, R. (2017b). Technology Foundations for Digital Development. Retrieved from https://ict4dblog.wordpress.com/2017/03/14/technology-foundations-for-digital-development/

Higgins, K. L. (2013). Economic growth and sustainability - are they mutually exclusive? Striking a balance between unbounded economic growth and sustainability requires. Retrieved May 28, 2016, from https://www.elsevier.com/connect/economic-growth-and-sustainability-are-they-mutually-exclusive

Hilty, L., \& Aebischer, B. (2015). ICT Innovations for Sustainability. London: Springer.

Hilty, L. M., \& Hercheui, M. D. (2014). ICT and Sustainable Development. Retrieved February 2, 2017, from https://hal.inria.fr/hal-01054793/document

Http://gesi.org. (2008). The contribution the ICT industry can make to sustainable development. Retrieved January 23, 2017, from http://gesi.org/report/detail/the-contribution-the-ict-industry-can-make-tosustainable-development

Http://staging.unep.org. (1972). Declaration of the United Nations Conference on the Human Environment. Retrieved June 3, from http://staging.unep.org/Documents.Multilingual/Default.Print.asp?DocumentID=97\&ArticleID=1503\&l=en Http://systemtransformation-sdg.gesi.org/. (2016). \#SystemTransformation: How Digital Solutions will Drive Progress towards the Sustainable Development Goals. Retrieved January 23, 2017, from http://systemtransformation-sdg.gesi.org/160608_GeSI_SystemTransformation.pdf

Http://www.un-documents.net. (1987). Our Common Future. Retrieved July 30, 2014, from http://www.undocuments.net/ocf-02.htm

Http://www.un.org. (2015). The Millennium Development Goals Report 2015. Retrieved June 3, 2016, from http://www.un.org/millenniumgoals/2015_MDG_Report/pdf/MDG 2015 rev (July 1).pdf

Https://portals.iucn.org. (1980). World Conservation Strategy. Retrieved February 15, 2017, from https://portals.iucn.org/library/efiles/documents/wcs-004.pdf

Https://sustainabledevelopment.un.org. (2015). Transforming our World: The 2030 Agenda for Sustainable Development. Retrieved June 3, 2016, from https://sustainabledevelopment.un.org/content/documents/21252030 Agenda for Sustainable Development web.pdf

Https://unwin.wordpress.com. (2015). ICTs and the failure of the Sustainable Development Goals. Retrieved January 23, 2017, from https://unwin.wordpress.com/2015/08/05/icts-and-the-failure-of-the-sustainabledevelopment-goals/

Https://www.ihrb.org. (2015). State of Play Business and the Sustainable Development Goals: Mind the Gap Challenges for Implementation. Retrieved May 28, 2016, from https://www.ihrb.org/pdf/state-ofplay/Business-and-the-SDGs.pdf

Https://www.microsoft.com. (2016). Microsoft and the UN Sustainable Development Goals. Retrieved January 23, 2017, from https://www.microsoft.com/en-us/about/corporate-responsibility/un-sdgs 
Jackson, T. (2009). Prosperity without growth?The transition to a sustainable economy. Retrieved from http://www.sd-commission.org.uk/data/files/publications/prosperity_without_growth_report.pdf

Jones, P., Comfort, D., \& Hillier, D. (2011). Sustainability in the global shop window. International Journal of Retail \& Distribution Management, 39(4), 256-271. http://doi.org/10.1108/09590551111117536

Jones, P., Hillier, D., \& Comfort, D. (2014). Sustainability in the global hotel industry. International Journal of Contemporary Hospitality Management, 26(1), 5-17. http://doi.org/10.1108/IJCHM-10-2012-0180

Morhardt, J. E. (2010). Corporate social responsibility and sustainability reporting on the Internet. Business Strategy and the Environment, 19(7), 436-452. http://doi.org/10.1002/bse.657

Newell, G. (2008). The strategic significance of environmental sustainability by Australian-listed property trusts. Journal of Property Investment \& Finance, 26(6), 522-540. http://doi.org/10.1108/14635780810908370

Porter, M. E., \& Kramer, M. E. (2006). Strategy and Society: The Link Between Competitive Advantage and Corporate Social Responsibility. Harvard Business Review.

PricewaterhouseCoopers. (2015). Make it your business: Engaging with the Sustainable Development Goals. Retrieved May 28, 2016, from https://www.pwc.com/gx/en/sustainability/SDG/SDG Research_FINAL.pdf

Ramirez, G. A. (2012). Sustainable development: paradoxes, misunderstandings and learning organizations. The Learning Organization, 19(1), 58-76. http://doi.org/10.1108/09696471211190365

Rivera, A. C., \& Kurnia, S. (2015). Exploring the roles of ICT in supporting sustainability practices. In Australasian Conference on Information Systems. Adelaide, Australia. Retrieved from https://acis2015.unisa.edu.au/wpcontent/uploads/2015/11/ACIS_2015_paper_50.pdf

Rokhmawati, A., \& Gunardi, A. (2017). Is going green good for profit? Empirical evidence from listed manufacturing firms in Indonesia. International Journal of Energy Economics and Policy, 7(4), 181-192.

Roper, J., \& Collins, E. (2016). Sustainability, hegemony and the dialectics of change. In 32nd EGOS Colloquium. Naples, Italy.

Rouse, M. (2005). ICT (information and communications technology, or technologies). Retrieved March 21, 2017, from http://searchcio.techtarget.com/definition/ICT-information-and-communications-technologyor-technologies

Sachs, J. (2016). Sustainable development: a new kind of globalization. Retrieved February 12, 2017, from https://www.bostonglobe.com/opinion/2016/07/18/sustainable-development-new-kindglobalization/8n33gJUKfUVDyMUD3J5iJK/story.html

Sachs, J., Modi, V., Figueroa, H., Machado, M., Sanyal, K., Khatun, F., ... Reid, K. (2016). How Information and Communications Technology can Accelerate Action on the Sustainable Development Goals. The Earth Institute Columbia University, Ericsson. Retrieved from https://www.ericsson.com/assets/local/news/2016/05/ict-sdg.pdf

Saunders, M., Lewis, P., \& Thornhill, A. (2009). Research methods for business students (5th ed.). Harlow: Pearson Education Limited.

Schor, J. B. (2005). Prices and quantities: Unsustainable consumption and the global economy. Ecological Economics, 55(3), 309-320. http://doi.org/10.1016/j.ecolecon.2005.07.030

Souter, D., MacLean, D., Okoh, B., \& Creech, H. (2010). ICTs, the Internet and Sustainable Development: Towards a new paradigm. International Institute for Sustainable Development, 1-39. Retrieved from https://www.iisd.org/pdf/2010/icts_internet_sd_new_paradigm.pdf

Tongia, R., Subrahmanian, E., \& Arunachalam, V. S. (2005). Information and Communications Technology for Sustainable Development: Defining a Global Research Agenda. Bangalore: Allied Publishers.

\section{Authors Note}

Sadly, David Hillier died, following a short illness, after the first draft of this paper was completed. 